\title{
Dependence of the throughput of drain pipes of different cross-section
}

\author{
Victoria Nemchaninova ${ }^{1, *}$ and Dmitriy Spitsov ${ }^{2}$ \\ ${ }^{1}$ Peter the Great St. Petersburg Polytechnic University, Polytechnicheskaya Street, 29, Saint \\ Petersburg, 195251, Russia \\ ${ }^{2}$ Moscow State University of Civil Engineering, Yaroslavskoye Shosse, 26, Moscow, 129337, Russia
}

\begin{abstract}
Flat drain pipes are a modern drainage solution. The flat profile increases the strength and rigidity of the pipe. The paper considers the experience of using flat pipes for drainage of territories in the whole world. A study of the dependence of the throughput of flat drain pipes on the slope was carried out, and a comparison was made with the throughput of round pipes. With the help of roughness, calculations of the throughput of flat and round pipes were made, and the low throughput of the section of a flat corrugated pipe compared to a round one was proved. A comparison of the efficiency of using pipes of different cross-sections is made using the example of wall drainage. The inexpediency of using flat drain pipes as wall drainage has been substantiated.
\end{abstract}

\section{Introduction}

When improving the territory, an important issue is the creation of a full-fledged system for drainage of rain and melt water, taking into account the terrain, sewerage systems, drainage ditches or an inspection well of the street network, as well as the presence of underground floors and premises. This issue is solved with the help of a drainage system.

Drainage is a system of interconnected drain pipes that are laid with a slope towards the water receiver around or along the structure. The drain pipe is a pipe with a special network of holes located at a certain distance from each other.

Flat drain pipes are a modern drainage solution. Due to the flat profile, the pipes have high strength and rigidity, and are easy to transport. Also, flat drain pipes can be mounted in two projections: vertically and horizontally, which will allow drainage of paths of complex shapes and reduce the amount of earthwork. Drain flat pipes, like pipes of round cross-section, are mounted with a geotextile filter to prevent clogging of the drainage system.

The advantages of flat drain pipes are comparable to the disadvantages of round ones:

- High strength of flat drain pipes;

- Easy transportation;

- The drainage capacity of a flat drain pipe $160 \times 40 \mathrm{~mm}$ is comparable to $\mathrm{d} 160 \mathrm{~mm}$.

Due to the relevance of studying the throughput of pipes and their application, more and more papers related to the study of flat drain pipes are published. So, Kudryavtsev A.V. and

\footnotetext{
* Corresponding author: vnemchaninova@gmail.com
} 
Fedorova C.V. examine in their paper the throughput of corrugated flat drain pipes using mathematical modeling in a finite element analysis package and prove the good throughput of the flat pipe wall. According to the results of a laboratory experiment on a hydraulic flume, the low discharge capacity of the cross-section of a flat pipe in comparison with a round one is proved [1].

In the work of Aliyev Z.G., the solution of the problems of determining the potential throughput of pipes in a closed network is considered A fundamentally new method for calculating the regularity of the distribution of velocities in pipes is derived, on the basis of which a new formula for the resistance to flow movement in pipes is obtained. When using the obtained formulas, a more correct calculation is performed [2].

Recently, new corrugated pipes with a flat profile have been used in Russia (Fig. 1). Flat pipes were first developed and used by road authorities in Australia to prevent premature road failure caused by slow work of drainage systems [3]. In North Carolina and the United States, flat pipes are used in artificial drainage systems to control groundwater levels in coastal landscapes [4]. In Russia, flat pipes are used in gardening.

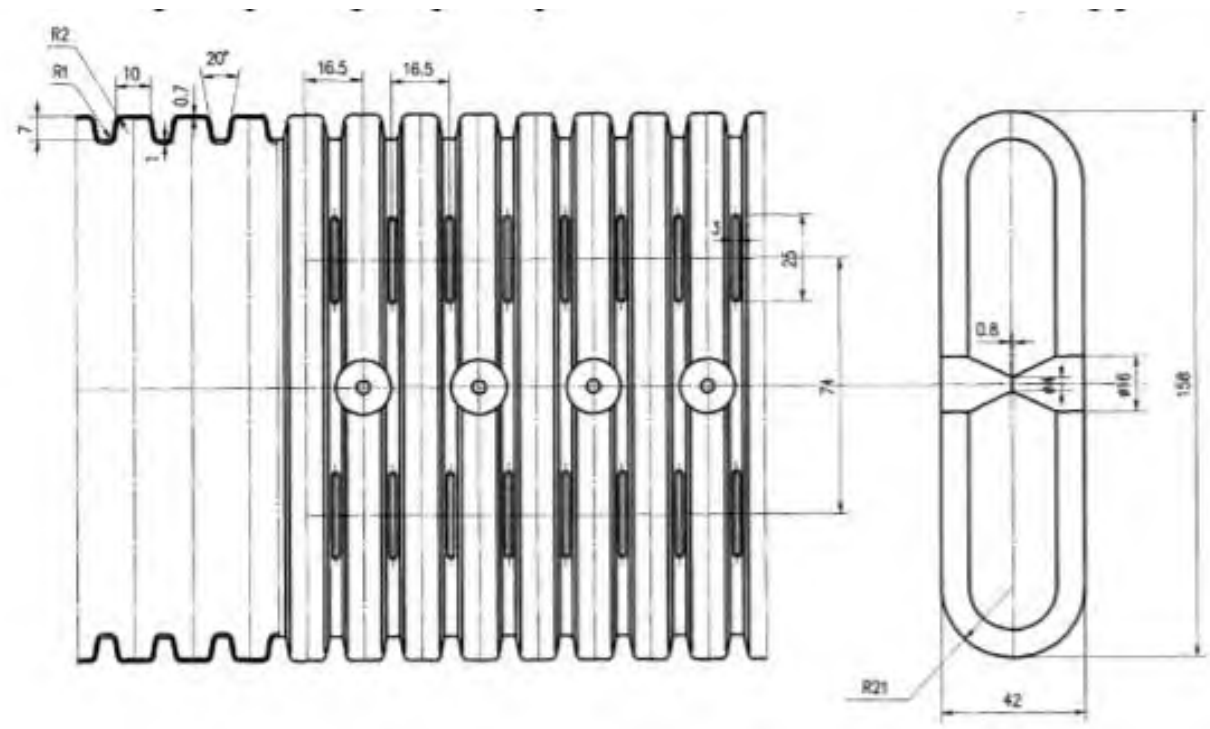

Fig. 1. Flat drain pipe

The purpose of this study is to test the hypothesis of a large capacity of a flat corrugated drain pipe in comparison with existing analogues - round corrugated drain pipes of various diameters. To achieve this goal, the following tasks were set:

- The calculation of the main hydraulic characteristics of pipelines of different crosssections was made;

- Determine the dependence of the speed of fluid movement and throughput on the slope at different filling of the pipe;

- Compare the efficiency of using pipes of different cross-sections using the example of wall drainage;

- Draw conclusions about the throughput and efficiency of using a flat corrugated pipe;

\section{Materials and methods}

The tasks posed in the work were solved based on the use of empirical research methods within the framework of a comparative analysis of pipes of different cross-sections. For 
comparison, corrugated drain pipes with diameters of 110 and $160 \mathrm{~mm}$ and a flat corrugated pipe with dimensions of 160x40 $\mathrm{mm}$ and a wall thickness of $2 \mathrm{~mm}$ were taken.

\subsection{Determination of the throughput of pipes}

To obtain information about the throughput of drain pipes, the formula for constant flow rate (1) and the Chezy formula (2) are used.

$$
\begin{gathered}
q=w \cdot V \\
V=C \sqrt{R_{i}}
\end{gathered}
$$

Where $q$ - estimated consumption; $w$; - free area; $V$ - velocity; $\mathrm{C}$ - Chezy coefficient; $R$ - hydraulic radius; $X$ - wetted perimeter; $i=h_{l} / L$ - flume slope; $h_{l}$ - fall of the flume at length $L$.

The hydraulic slope $L$ according to the Chezy formula is equal to the flume slope $i$, since there is a uniform movement of water. To determine the Chezy coefficient, the Pavlovsky formula (3) is used (for $0.1<\mathrm{R}<3 \mathrm{~m}$ ).

$$
C=\frac{R^{y}}{n}
$$

For rough calculations, Pavlovsky recommended the following formulas $(4,5)$ :

$$
\begin{aligned}
& y \approx 1.5 \sqrt{n} \text { for } 0.1<R<1.0 \\
& y \approx 1.3 \sqrt{n} \text { for } 1.0<R<3.0
\end{aligned}
$$

Where $\mathrm{y}$ - exponent; $\mathrm{n}=0.012$ - roughness coefficient which depends on pipe walls.

Table 1. Formulas for calculating pipes of different cross-sections

\begin{tabular}{|c|c|c|}
\hline \multicolumn{2}{|c|}{ Round pipe } & Flat pipe \\
\hline $110 \mathrm{~mm}$ & $160 \mathrm{~mm}$ & $160 \mathrm{x} 40 \mathrm{~mm}$ \\
\hline$W=\frac{\pi \cdot d^{2}}{4}$ & $W=\frac{\pi \cdot d^{2}}{4}$ & $W=a \cdot b$ \\
\hline \multicolumn{3}{|c|}{ Wetted perimeter } \\
\hline$X=\pi \cdot d$ & $X=\pi \cdot d$ & $X=2 \cdot a+2 \cdot b$ \\
\hline \multicolumn{3}{|c|}{ Wetted perimeter for unfilled pipe } \\
\hline$R=\frac{\pi \cdot d \cdot \varphi}{360^{\circ}}$ & $X=\frac{\pi \cdot d \cdot \varphi}{360^{\circ}}$ & $X=2 \cdot a+\mathrm{c}$ \\
\hline$X=\frac{\pi \cdot d^{2}}{4 \cdot \pi \cdot d}$ & Hydraulic radius \\
\hline
\end{tabular}

The calculation of the main hydraulic characteristics of pipelines of different crosssections is made. The calculation results are shown in table 2 .

Table 2. Hydraulic characteristics

\begin{tabular}{|l|l|l|}
\hline Round pipe, $110 \mathrm{~mm}$ & Round pipe, $160 \mathrm{~mm}$ & Flat pipe \\
\hline
\end{tabular}




\begin{tabular}{|c|c|c|}
\hline$W=0.00882 \mathrm{~m}^{2}$ & $W=0.0191 \mathrm{~m}^{2}$ & $W=0.0042 \mathrm{~m}^{2}$ \\
\hline$X=0.33284 \mathrm{~m}$ & $X=0.48984 \mathrm{~m}$ & $X=0.376 \mathrm{~m}$ \\
\hline$R=0.0265 \mathrm{~m}$ & $R=0.039 \mathrm{~m}$ & $R=0.01117 \mathrm{~m}$ \\
\hline
\end{tabular}

\subsection{Calculation of wall drainage}

Wall drainage serves to protect the underground part of the building, which are located in clay or watered soil, as well as when the aquiclude is close. Wall drainage is laid along the wall and along the outer contour of the building at the level of the foot of the foundation [7]. The minimum distance from the building wall to the axis of the drain pipe is calculated using the formula (6):

$$
L=l_{1}+l_{2}
$$

Where $l_{1}$ - distance from the surface of the building wall to the wall of the drain pipe (minimum $0.15 \mathrm{~m}$ );

$$
l_{2}=0.5 \cdot d_{\text {pipe }}
$$

- half the diameter of the drain pipe.

$$
l_{2}=0.5 \cdot \sqrt{\frac{W \cdot 4}{\pi}}
$$

- the same value for a flat drain pipe.

Let's take the distance from the surface of the building wall to the wall of the round drain pipe equal to $0.23 \mathrm{~m}$, for a flat one $-0.18 \mathrm{~m}$. The depth of the drain is assumed to be $1.57 \mathrm{~m}$. The design diagram of the wall drainage is shown in Fig. 1.

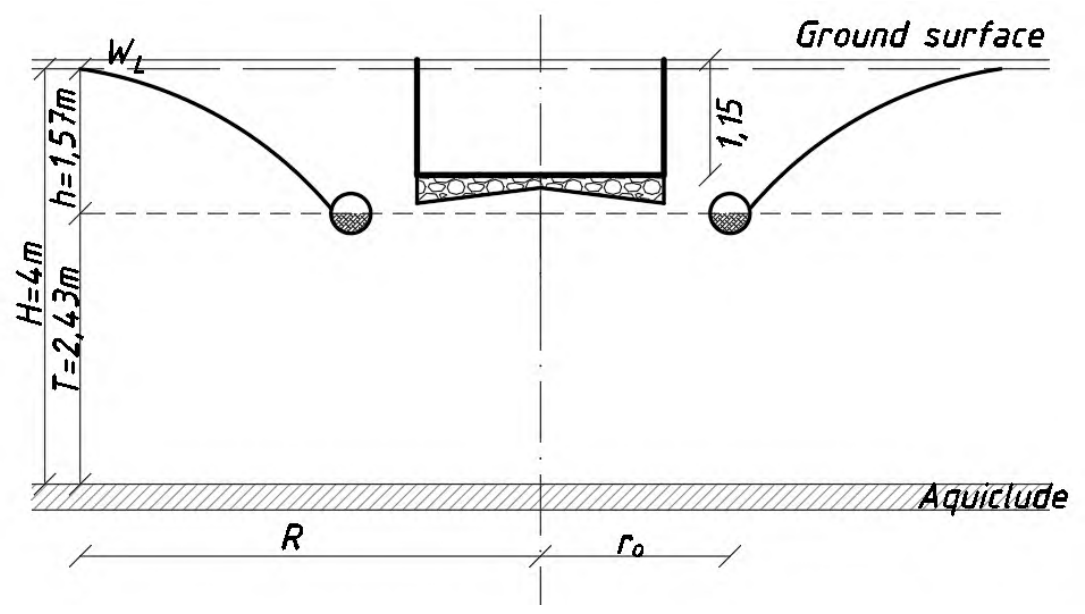

Fig. 1. Design scheme of wall drainage

In practical hydraulic calculations, the schematization of the planned position of the drainage consists in replacing the real area located inside the drainage system contour with the area of the design circle with the conditional radius $r_{o}$. And is defined for wall drainage as half the width of the building. 
Depression radius - the area of the drainage system's influence zone, which is replaced by the calculated area with the conditional radius of the system's influence. The depression radius $R d$ is determined from the formula (9):

$$
R d \cdot \sqrt{\lg R d-\lg r_{o}-0.217}=0,66 \cdot \sqrt{\frac{K \cdot h^{2}}{W}-0.5 \cdot r_{o}}
$$

\section{Results and their discussion}

\subsection{Results of calculating the throughput of pipes}

Depending on the filling of the pipe, the speed of movement of the liquid and the throughput of the pipe change. To determine these parameters, the constant flow rate (1) and Chezy (2) formulas were used. The graphs of the dependence of the speed of fluid movement and the throughput of the pipe on the slope for different filling of the pipe were constructed.

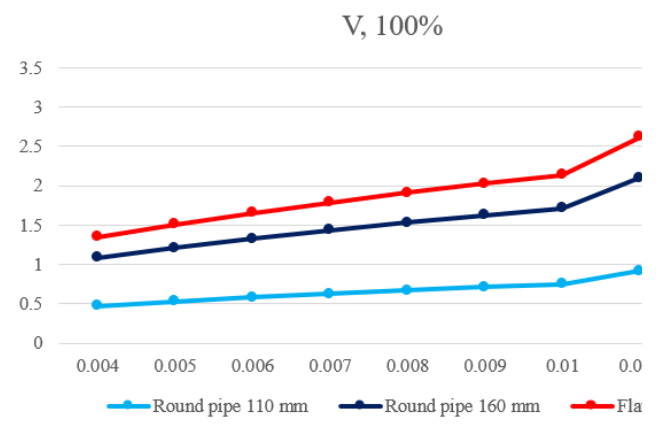

Fig. 2. Graph of the dependence of the speed of fluid on the slope at $100 \%$ fullness of the pipe

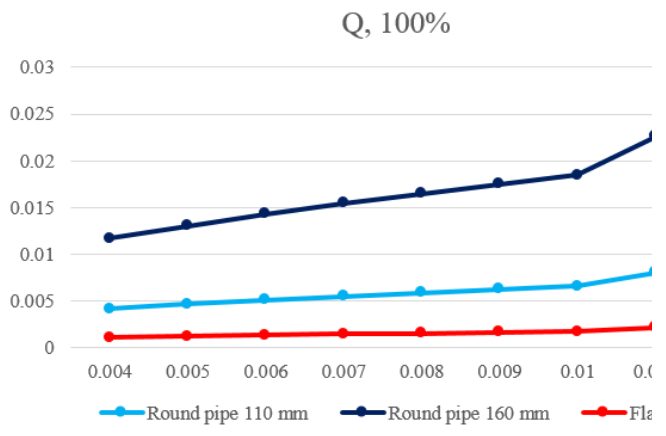

Fig. 3. Graph of the dependence of the throughput on the slope at $100 \%$ fullness of the pipe

According to the obtained dependencies (Fig. 2, 3), it can be seen that a flat pipe is inferior in terms of throughput to round pipes and has the highest fluid speed.

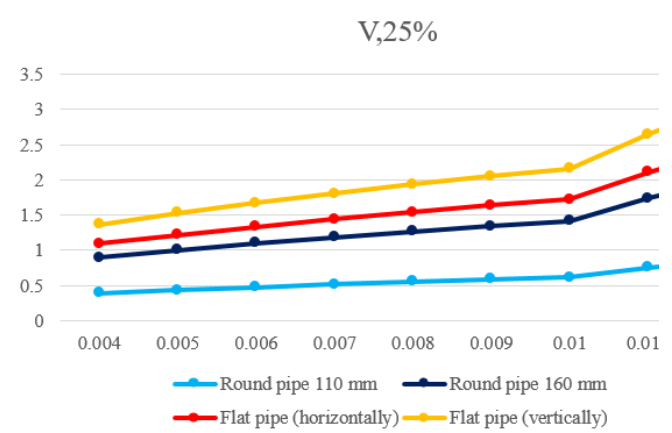

Fig. 4. Graph of the dependence of the speed of fluid on the slope at $25 \%$ fullness of the pipe

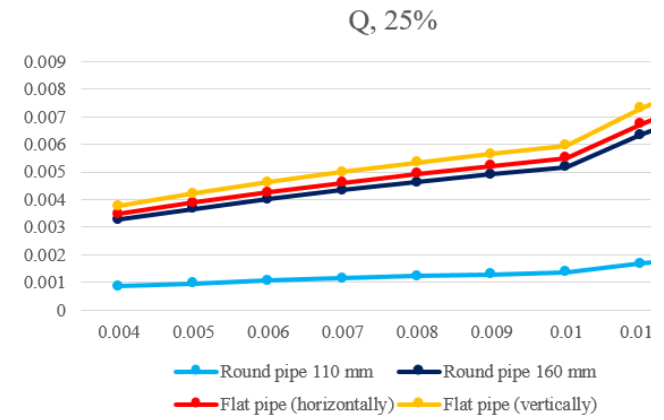

Fig. 5. Graph of the dependence of the throughput on the slope at $25 \%$ fullness of the pipe

In the case of pipe operation for $25 \%$, i.e. when $1 / 4$ is full, a flat pipe can be positioned both vertically and horizontally, because the orientation of the pipe affects the hydraulic radius. Therefore, the graphs show the dependence of two round pipes of different diameters and two positions of a flat pipe (Fig. 4,5). 
Similarly to the previous case, the fluid speed for a flat pipe is much higher than that for round pipes. The throughput of a flat pipe in this case slightly exceeds the throughput of a round pipe with a diameter of $160 \mathrm{~mm}$. The $110 \mathrm{~mm}$ pipe can pass significantly less liquid compared to other pipes in question.
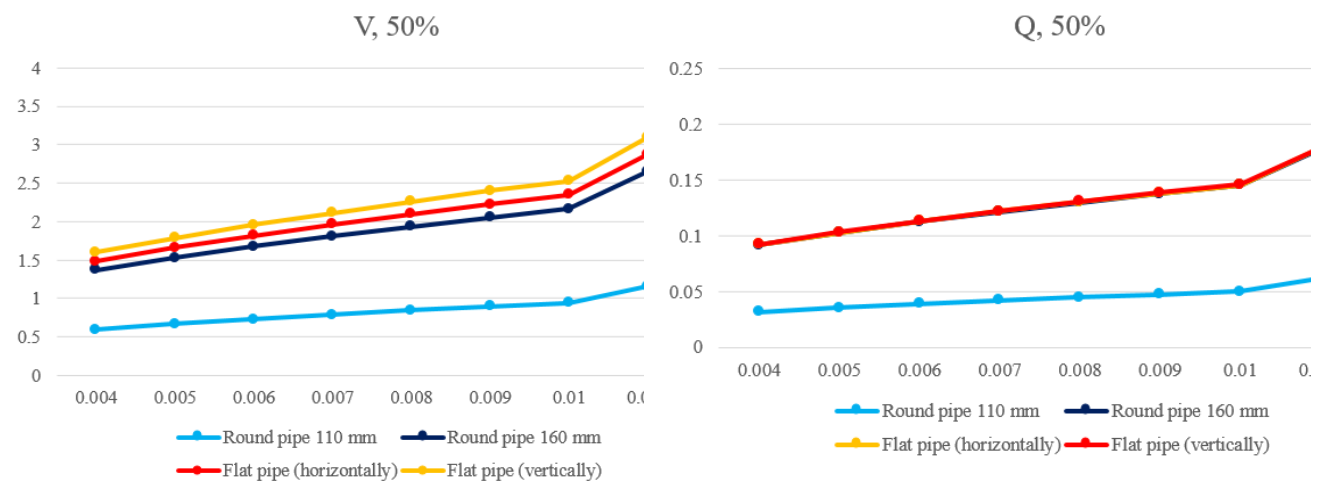

Fig. 6. Graph of the dependence of the speed of fluid on the slope at $50 \%$ fullness of the pipe

Fig. 7. Graph of the dependence of the throughput on the slope at $50 \%$ fullness of the pipe

Similarly to the previous case, the fluid speed for a flat pipe exceeds the speed for round pipes (Fig. 6.7). The throughput for different arrangements of a flat pipe and a round pipe with a diameter of $160 \mathrm{~mm}$ is the same. The most favorable operation of pipes in this case will be observed for a round pipe with a diameter of $160 \mathrm{~mm}$, because with the same volume of passing liquid, the speed of movement will be less than in a flat pipe.
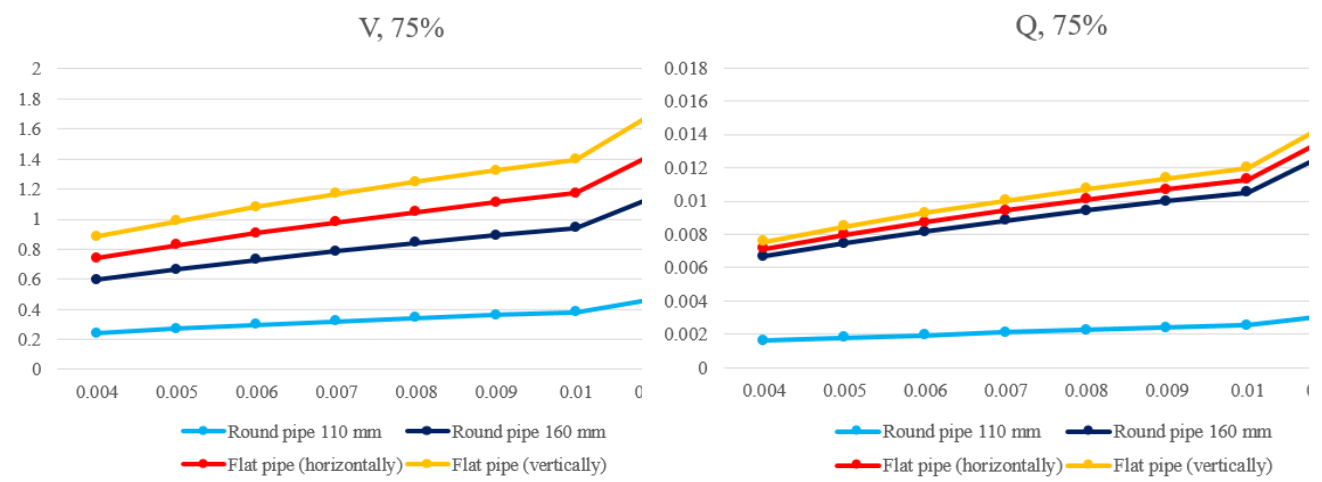

Fig. 8. Graph of the dependence of the speed of fluid on the slope at $75 \%$ fullness of the pipe

Fig. 7. Graph of the dependence of the throughput on the slope at $75 \%$ fullness of the pipe

Similarly to the previous case, the speed of fluid for a flat pipe is much higher than the speed for round pipes (Fig. 8.9). The throughput of a flat pipe is slightly higher than the throughput of a round pipe with a diameter of $160 \mathrm{~mm}$.

After analyzing the results obtained, it can be concluded that in all options for filling the pipe, the speed of fluid in a flat pipe is higher than in a pipe of round cross-section. This can negatively affect the pipe itself, increasing wear and decreasing service life.

\subsection{Results of calculating the wall drainage}

The minimum distance from the building wall to the drainage axis for a round pipe with a diameter of $160 \mathrm{~mm}$ was $0.23 \mathrm{~m}$, and for a flat pipe $-0.18 \mathrm{~m}$. In this case, the depression 
radius for a round pipe is $39.93 \mathrm{~m}$, and for a flat pipe $-20.33 \mathrm{~m}$. The radius of influence of a pipe with a round cross-section exceeds the radius of influence of a flat pipe.

It is also necessary to take into account the slope at which it is necessary to lay the drain pipes. To lay a flat drain pipe, it must be at least $3^{\circ}$ or $52.4 \%$ along its entire length, while the minimum slope for a round pipe is $4 \%$ [8]. Due to this, the deepening of a flat pipe at the end of the pipe relative to its beginning with a length of $10 \mathrm{~m}$ will be $0.524 \mathrm{~m}$, and for a round pipe $-0.04 \mathrm{~m}$. This difference will also lead to an increase in land work when laying the flat drain pipe.

\section{Conclusion}

1. Flat corrugated pipes in any position exhibit low flow rates compared to round pipes. Only in the case of a partially filled pipe do flat pipes have a capacity comparable to a round pipe with a diameter of $160 \mathrm{~mm}$. However, in all cases, the speed of fluid in a flat pipe, compared to a round one, is much higher. In general, round piping works more balanced, it is less prone to silting and is suitable for laying on any slope.

2. For wall drainage, the use of flat drainage pipes is impractical, because the depression radius of a flat pipe is half less than the depression radius of a round pipe, and the fluid speed is greater. Flat pipes are inferior to round ones in ease of maintenance and do not guarantee long-term operation. When laying a flat drain pipe, more excavation is required, which will increase the cost of the system. It is recommended to use flat pipes as short filter drains that will divert liquid into the main pipeline.

\section{References}

1. A. V. Kudryavtsev, S. V. Fedorov. The study of bandwidth flat drainage pipes. Veles. Kiev: Foundation For Economic Initiatives, 5-1(71), 90-98 (2019)

2. Z. G. Aliev, B. G. Aliev, A. F. Zeynalova, Improvement of the calculating method of the pipelines capacity of closed irrigative networks, BAKU: Bulletin of the kurgan state agricultural academy, 2(30), 4-9 (2019)

3. J. Roderick, Panel drains v Round pipe comparison, Fyfe Business Development Manager, Geotextiles and Drainage, Geofabrics A/Asia Pty.Ltd. Australia

4. B. Poulter, L. Jonathan, Applications of network analysis for adaptive management of artificial drainage systems in landscapes vulnerable to sea level rise Journal of Hydrology, 357, 207-2017 (2008)

5. V. A. Bolshakov, Handbook of hydraulics, 343 (Higher school. Head publishing house, 1984)

6. Hydraulic calculation of collectors. https://lektsii.org/4-24443.html (Last accessed 01.12.2020)

7. K. N. Criulin, Drainage systems in landscape and cottage construction, 122 (St. Petersburg: Green Arrow, 2014)

8. https://xn--80aa1agdk5a.xn--p1ai/product-description/ploskie-drenazhnye-truby (Last accessed 06.12.2020)

9. N. Martynov, et al. Journal of Physics: Conference Series 1614, 012060 (2020) doi:10.1088/1742-6596/1614/1/012060 